\title{
Mechanisms Underlying the Differential Effects of Ethanol on the Bioavailability of Riboflavin and Flavin Adenine Dinucleotide
}

\author{
John Pinto, Yee Ping Huang, and Richard S. Rivlin \\ Department of Medicine, Memorial Sloan-Kettering Cancer Center, New York 10021; and \\ Department of Medicine, Cornell University Medical College, New York 10021
}

\begin{abstract}
Chronic alcoholism is associated with a high prevalence of riboflavin deficiency. Experiments were designed in an animal model to determine whether ethanol alters selectively the absorption of riboflavin and flavin adenine dinucleotide (FAD), the predominant dietary form of the vitamin. Rats received by gavage a liver homogenate to which either $\left[{ }^{14} \mathrm{C}\right]$ riboflavin or $\left[{ }^{14} \mathrm{C}\right] \mathrm{FAD}$ was added with either ethanol or isocaloric sucrose solutions. Ethanol markedly diminished the bioavailability of $\left[{ }^{14} \mathrm{C} F \mathrm{FD}\right.$ to a greater degree than that of $\left[{ }^{14} \mathrm{C}\right]$ riboflavin. Corroboration of an ethanol-impaired intraluminal hydrolysis of FAD was provided by using everted jejunal segments and measuring mucosal uptake of $\left[{ }^{14}\right.$ C]riboflavin together with nonradiolabeled FAD. In subsequent studies with mucosal cell extracts, ethanol markedly inhibited activities of FAD pyrophosphatase and flavin mononucleotide (FMN) phosphatase. These findings suggest that dietary sources of riboflavin (FMN and FAD) are not absorbed as well in the presence of ethanol than are vitamin preparations containing riboflavin, which is utilized more readily.
\end{abstract}

\section{Introduction}

Numerous reports have documented a high prevalence of riboflavin (vitamin $B_{2}$ ) deficiency in alcoholic patients (1-8). In some instances, flagrant manifestations of clinically advanced deficiency are apparent in the form of glossitis and cheilosis (4, 5). More commonly, evidence of deficiency is based upon biochemical laboratory tests, including decreased urinary excretion of riboflavin, low serum levels of riboflavin, and elevated activity coefficient of erythrocyte glutathione reductase, an enzyme marker for riboflavin deficiency (9-11). Estimates of the prevalence of riboflavin deficiency among alcoholics have generally varied between 15 and $50 \%$ based on the laboratory and clinical evidence examined $(2,5)$. Deficits of riboflavin in alcoholism could lead to skin disorders (12), changes in metabolism of xenobiotic substances $(13,14)$, abnormalities of endocrine function (15-18), disturbances in lipid metabolism $(19,20)$, interference with energy utilization (21), and personality deterioration $(22,23)$.

Lack of riboflavin in alcoholics has usually been observed in association with deficiencies of other nutrients (1, 3, 24-26), perhaps because a diet poor in one nutrient is generally poor in

Address reprint requests to Dr. John Pinto, Memorial Sloan-Kettering Cancer Center, 1275 York Avenue, Box 140, New York, NY 10021.

Received for publication 8 November 1986 and in revised form 7 January 1987.

J. Clin. Invest.

(c) The American Society for Clinical Investigation, Inc.

$0021-9738 / 87 / 05 / 1343 / 06 \quad \$ 1.00$

Volume 79, May 1987, 1343-1348 others. Furthermore, since riboflavin is involved in the metabolic transformations of folic acid $(27,28)$, pyridoxine $(29,30)$, vitamin K (31), and niacin (32), decreased dietary intake of riboflavin would also increase the likelihood of developing either secondary deficiencies or alterations in metabolism of these vitamins.

Despite widespread recognition that riboflavin deficiency is a common feature of alcoholism, little is understood of its pathogenesis. It is not known whether riboflavin deficiency under these circumstances is due entirely to inadequate dietary intake of this key vitamin, or whether alcohol exerts specific and direct effects on metabolism of riboflavin or of any of its derivatives. In general, vitamin deficiencies in alcoholism, are attributed to diminished intake, decreased absorption, and disturbances in metabolism (33). To elucidate possible mechanisms underlying the pathogenesis of riboflavin deficiency in alcoholism, we have considered an animal model in which riboflavin and its coenzymic forms can be fed both in the presence and absence of alcohol, and flavin utilization can be determined subsequently. These studies indicate that ethanol greatly diminishes the bioavailability of riboflavin from the gastrointestinal tract, and particularly that of flavin adenine dinucleotide (FAD), ${ }^{1}$ the form of riboflavin predominantly present in food sources. By inhibiting the FAD degradative enzymes in intestinal mucosa, alcohol and its metabolite, acetaldehyde, either singly or in combination diminish the conversion of FAD to riboflavin, the form required for absorption.

\section{Methods}

Animals and diet. All experiments were performed on adult male rats (Holtzman Co, Madison, WI) weighing 150-250 g. Animals used in these experiments were maintained on tap water and standard pelleted Purina Rat Chow ad lib. (Ralston Purina Co., St. Louis, MO), which has been determined in this laboratory to contain riboflavin in $\sim 8.5$ $\mu \mathrm{g} / \mathrm{g}$ diet. Animals consuming this diet in normal amounts receive three times the recommended daily allowance for riboflavin in the rat.

Isotopes and chemicals. $28 \mathrm{mCi} / \mathrm{mmol}\left[{ }^{14} \mathrm{C}\right]$ riboflavin was purchased from Amersham Corp., Arlington Heights, IL, and its specific activity assayed in this laboratory before use. Nonradioactive riboflavin, riboflavin-5'-phosphate (flavin mononucleotide [FMN]), and FAD were purchased from Sigma Chemical Co., St. Louis, MO. All other chemicals were of the highest grade available commercially.

Alcohol administration and $\left[{ }^{14} C\right] F A D$ formation in liver. Before all experiments, a normal rat was decapitated, and a liver homogenate prepared ( $1 \mathrm{~g}$ liver per $2 \mathrm{ml}$ water). Liver was selected as the model food source because, of all the common foods, it has the highest concentration of phosphorylated derivatives of riboflavin (as FMN and FAD) (17). To this homogenate was added $1.4 \times 10^{5} \mathrm{dpm} / \mathrm{ml}\left[{ }^{14} \mathrm{C}\right]$ riboflavin and either ethanol to a final concentration of $20 \%$ or sucrose in an amount isocaloric with $20 \%$ ethanol. These preparations were used in subsequent alcohol

1. Abbreviations used in this paper: FAD, flavin adenine dinucleotide; FMN, flavin mononucleotide. 
studies by intubation. Animals used in the feeding experiments were fasted for $18 \mathrm{~h}$ before intubation. Each animal received an aliquot of the liver homogenate that contained $\left[{ }^{14} \mathrm{C}\right]$ riboflavin and $15 \mathrm{ml} / \mathrm{kg}$ body weight of either ethanol or sucrose by gavage. In further experiments, $1.4 \times 10^{5}$ $\mathrm{dpm} / \mathrm{ml}\left[{ }^{14} \mathrm{C}\right] \mathrm{FAD}$ was substituted for $\left[{ }^{14} \mathrm{C}\right]$ riboflavin and a similar procedure followed. When maintained at $4^{\circ} \mathrm{C}$ before intubation, the ethanolic $\left[{ }^{14} \mathrm{C}\right] \mathrm{FAD}$-containing liver homogenate contained negligible activities of FAD pyrophosphatase and FMN phosphatase, which were monitored by thin layer chromatographic separation of radiolabeled flavin derivatives.

Rats were decapitated at 2,4 , and $6 \mathrm{~h}$ after gastric intubation. Livers were removed promptly and assayed for $\left[{ }^{14} \mathrm{C}\right] \mathrm{FAD}$ by using reverseisotope dilution and anion-exchange column chromatography with DEAE-Sephadex A-25 (Pharmacia Fine Chemicals, Division of Pharmacia Inc., Piscataway, NJ), as published previously from this laboratory (34).

Preparation and mounting of everted intestinal segments and in vitro transport of $\left[{ }^{14} \mathrm{C}\right]$ riboflavin. To demonstrate selective effects of ethanol and acetaldehyde directly upon the luminal phase of flavin absorption, we examined the uptake of $\left[{ }^{14} \mathrm{C}\right]$ riboflavin both in the presence and absence of 100-fold excess of nonradiolabeled FMN and FAD in isolated everted jejunal segments. Intestinal segments were prepared and jejunal sleeves were mounted using the procedure of Karasov and Diamond (35). Jejunal segments were incubated at $37^{\circ} \mathrm{C}$ in mammalian Ringer's solution that contained $2.5 \mathrm{mM}$ phenylalanine, which inhibits intestinal alkaline phosphatase but has no effect on FAD pyrophosphatase and minimal effect on FMN phosphatase activities [36]. Before incubation of the rod-mounted sleeves, Ringer's media that contained $31.3 \mathrm{nCi} / \mathrm{ml}$ $\left[{ }^{14} \mathrm{C}\right]$ riboflavin alone or with either of the phosphorylated flavin derivatives (0.115 mM FMN or $0.124 \mathrm{mM}$ FAD) were prepared to final dilutions with Ringer's solution, $10 \%$ ethanol, or $0.2 \%$ acetaldehyde and gassed with $5 \% \mathrm{CO}_{2}-95 \% \mathrm{O}_{2}$. After $20 \mathrm{~min}$, incubations were terminated at timed intervals by removing the rod-mounted sleeves from incubation vessels and successively rinsing them for $15 \mathrm{~s}$ each in three beakers of $50 \mathrm{ml}$ cold Ringer's solution without tracer. This postincubation rinse time was sufficient to remove adherent extracellular $\left[{ }^{14} \mathrm{C}\right]$ riboflavin. Tissue samples were drained of excess media by touching the tips of the rodmounts to filter paper. Mounted tissues were cut from between the sutures with a scalpel, placed in tared glass scintillation vials, and weighed (80$120 \mathrm{mg}$ ). All samples were prepared for counting by first incubating tissue at $100^{\circ} \mathrm{C}$ for $2 \mathrm{~h}$ in $1 \mathrm{~N} \mathrm{NaOH}$ and then allowing vials to sit at room temperature overnight. After complete tissue solubilization (10$18 \mathrm{~h}$ ), each sample was neutralized with $\mathrm{HCl}$, mixed with $10 \mathrm{ml}$ Hydrofluor (National Diagnostics, Inc., Advanced Applications Institute Inc., Somerville, NJ), and radioactivity determined in a Tricarb liquid scintillation spectrometer (Packard Instrument Co. Inc., Downers Grove, IL). $\left[{ }^{14} \mathrm{C}\right]$ Riboflavin uptake per intestinal segment was determined as disintegrations per minute per milligram wet weight of tissue, and all incubations and procedures that involved riboflavin and its phosphorylated derivatives were performed under reduced lighting.

$F A D$ pyrophosphatase and $F M N$ phosphatase assay in intestinal mucosal cells. Rats were fasted for $18 \mathrm{~h}$ before decapitation. The small intestine was removed promptly and rinsed with cold saline. The mucosal tissue was scraped off gently with a glass slide at $4^{\circ} \mathrm{C}$. The cellular scrapings were homogenized for $30 \mathrm{~s}$ with iced $0.1 \mathrm{M}$ Tris buffer, $\mathrm{pH} 8$. The mucosal extracts were then centrifuged at $60,000 \mathrm{~g}$ for $30 \mathrm{~min}$, and the supernatant solution decanted and used for enzymatic assay.

To assay FAD pyrophosphatase, aliquots of the supernatant solutions were incubated at $37^{\circ} \mathrm{C}$ for $20 \mathrm{~min}$ with $0-20 \%$ ethanol or $0-2 \%$ acetaldehyde, and $6,000-8,000 \mathrm{dpm}\left[{ }^{14} \mathrm{C}\right] \mathrm{FAD}$ to a total volume of $0.5 \mathrm{ml}$. Boiled supernatant solutions were used as blanks, and all reaction mixtures were preincubated at room temperature for $5 \mathrm{~min}$ before initiating the reaction with radiolabeled FAD. The enzymic reaction was stopped with $7 \mathrm{ml}$ absolute methanol. To assay FMN phosphatase, $\left[{ }^{14} \mathrm{C}\right] \mathrm{FMN}$ was substituted for $\left[{ }^{14} \mathrm{C}\right] \mathrm{FAD}$.

To each flask that contained the terminated reaction mixture, 1.0$\mathrm{ml}$ vol of nonradioactive FAD, FMN, and riboflavin in amounts of 100 $\mu \mathrm{g} / \mathrm{ml}$ were added. Solutions were evaporated to dryness, taken up in 1 $\mathrm{ml}$ of $1 \%$ ammonium sulfate, and chromatographed on a column of DEAE-Sephadex A-25. Radioactive bands for $\left[{ }^{14} \mathrm{C}\right] \mathrm{FAD},\left[{ }^{14} \mathrm{C}\right] \mathrm{FMN}$, and $\left[{ }^{14} \mathrm{C}\right]$ riboflavin were recovered in graduated vessels, and an aliquot removed for counting in a liquid scintillation spectrometer (Packard Instrument $\mathrm{Co}$. Inc.). FAD pyrophosphatase and FMN phosphatase activities were determined as the loss of disintegrations per minute FAD/20 $\mathrm{min}$ and formation of disintegrations per minute riboflavin/20 min, respectively. Data are shown as percent of control in the presence of either ethanol or acetaldehyde.

\section{Results}

$\left[{ }^{14} \mathrm{C}\right]$ Riboflavin as vitamin source. At intervals after rats' stomachs were intubated with a liver homogenate that contained $\left[{ }^{14} \mathrm{C}\right]$ riboflavin and an equal volume of added sucrose, radiolabeled riboflavin was incorporated briskly into $\left[{ }^{14} \mathrm{C}\right] \mathrm{FAD}$ in their liver. Isotope incorporation increased progressively at 2,4 , and $6 \mathrm{~h}$ postintubation, as shown in Fig. 1. In subsequent studies in which the homogenates were mixed with water rather than sucrose, an identical pattern of incorporation into $\left[{ }^{14} \mathrm{C}\right] \mathrm{FAD}$ was noted.

Fig. 1 also shows the effect of intubating rats with the liver homogenate that contain $\left[{ }^{14} \mathrm{C}\right]$ riboflavin and an isocaloric amount of $20 \%$ ethanol to replace sucrose. It is evident that consumption of ethanol reduces hepatic incorporation of $\left[{ }^{14} \mathrm{C}\right]$ riboflavin into $\left[{ }^{14} \mathrm{C}\right] \mathrm{FAD}$ by $\sim 50 \%$ at each of the three time points, 2,4 , and $6 \mathrm{~h}$.

$\left[{ }^{14} C\right] F A D$ as vitamin source. To compare the effects of ethanol on incorporation of dietary $\left[{ }^{14} \mathrm{C}\right]$ riboflavin and $\left[{ }^{14} \mathrm{C}\right] \mathrm{FAD}$ into liver $\left[{ }^{14} \mathrm{C}\right] \mathrm{FAD}$, identical experiments were conducted with radioactive FAD substituted for radioactive riboflavin as a vitamin source. When the liver homogenate contained $\left[{ }^{14} \mathrm{C}\right] \mathrm{FAD}$ and sucrose, the rate of incorporation into $\left[{ }^{14} \mathrm{C}\right] \mathrm{FAD}$ after gastric intubation was similar to that with $\left[{ }^{14} \mathrm{C}\right]$ riboflavin as a nutrient source (Fig. 2). Incorporation of dietary $\left[{ }^{14} \mathrm{C}\right] \mathrm{FAD}$ into hepatic $\left[{ }^{14} \mathrm{C}\right] \mathrm{FAD}$ (dpm/100 mg tissue) increased progressively from 2 to $6 \mathrm{~h}$.

Results of replacement of sucrose by $20 \%$ ethanol are also shown in Fig. 2. Simultaneous consumption of ethanol reduced incorporation of dietary FAD into hepatic FAD to less than half that of controls at 2 and $4 \mathrm{~h}$, and to half that of controls at $6 \mathrm{~h}$.

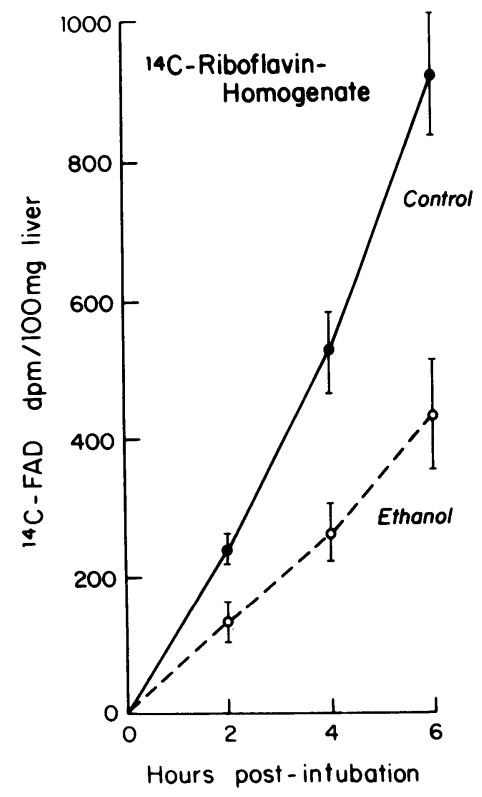

Figure 1. Rate of incorporation of $\left[{ }^{14} \mathrm{C}\right]$ riboflavin in a homogenate with either sucrose or ethanol into $\left[{ }^{14} \mathrm{C}\right] \mathrm{FAD}$ in rat liver at intervals after gastric intubation. 


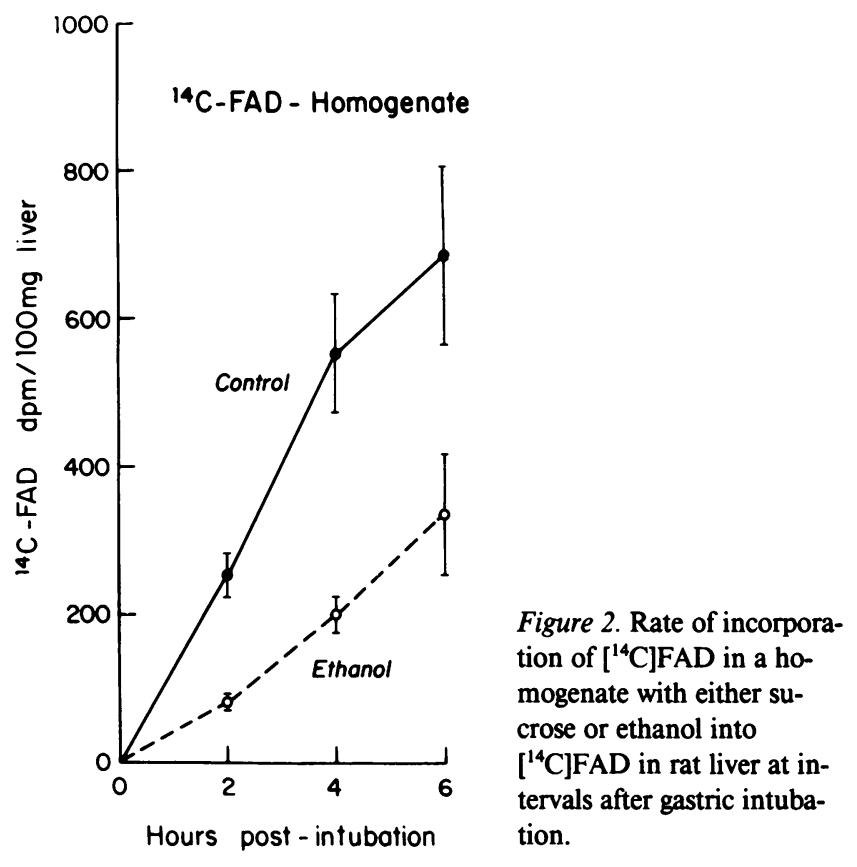

A summary of the effects of ethanol upon inhibiting the dietary utilization of riboflavin and FAD is shown in Table $I$. At 2 and $4 \mathrm{~h}$ post-gastric intubation with ethanol, dietary FAD incorporated into liver FAD is significantly less than with riboflavin as a vitamin source. At $6 \mathrm{~h}$, no significant difference appeared in hepatic FAD that formed in a small number of animals when fed FAD or riboflavin as a vitamin source, by gastric intubation. It is essential to note that at all times, and with all samples, the levels of alcohol feeding were $50 \%$ or less than those of sucrose-fed animals.

In vitro transport of $\left[{ }^{14} \mathrm{C}\right]$ riboflavin into everted jejunal segments. The finding that ethanol diminished the bioavailability of FAD to a greater extent than that of riboflavin, raised the possibility that ethanol might diminish the hydrolysis of dietary FAD to riboflavin, the form in which vitamin $B_{2}$ is absorbed from the intestine.

To test this hypothesis, we measured in everted intestinal segments the effects of ethanol and acetaldehyde directly on $\left[{ }^{14} \mathrm{C}\right]$ riboflavin uptake in the presence and absence of nonradiolabeled FAD and FMN (Fig. 3). Exogenous addition of excess FAD or FMN to the incubation media would be expected to dilute the radiolabeled riboflavin pool after dephosphorylation of FAD and FMN by FAD pyrophosphatase and FMN phos-

Table I. Comparison of the Effects of Ethanol on Bioavailability of Flavin Derivatives (Incorporation into Hepatic FAD) Administered to Rats by Gastric Intubation

\begin{tabular}{llll}
\hline & \multicolumn{2}{l}{ Hepatic $\left[{ }^{14} \mathrm{C}\right] \mathrm{FAD}$ formation } & \\
\cline { 2 - 3 } Postintubation & $\begin{array}{l}{\left[^{14} \mathrm{C}\right] \text { Riboflavin }} \\
\text { homogenate }\end{array}$ & $\begin{array}{l}{\left[{ }^{14} \mathrm{C}\right] \mathrm{FAD}} \\
\text { homogenate }\end{array}$ & $\begin{array}{l}\text { Significance } \\
\text { of difference }\end{array}$ \\
\hline$h$ & $\%$ control & $\%$ control & \\
2 & $56.4 \pm 1.7(17)^{*}$ & $31.0 \pm 2.0(20)$ & $P<0.001$ \\
4 & $51.0 \pm 1.6(10)$ & $36.5 \pm 0.5(14)$ & $P<0.001$ \\
6 & $47.3 \pm 8.4(3)$ & $49.3 \pm 2.8(8)$ & NS \\
\hline
\end{tabular}

* Figures in parentheses represent numbers of animals; data are expressed as mean $\pm \mathrm{SE}$. phatase, respectively. A schematic representation of the sequential dephosphorylation of FAD to riboflavin is outlined in Fig. 4. As illustrated in Fig. 3, intestinal segments incubated in Ringer's media alone demonstrated a marked uptake capacity for $\left[{ }^{14} \mathrm{C}\right]$ riboflavin. In the presence of 100 -fold excess of either nonradiolabeled FAD or FMN and subsequent dephosphorylation to riboflavin, intestinal segments demonstrated a significant reduction in uptake of radiolabeled riboflavin, attributable to subsequent dilution of the intracellular $\left[{ }^{14} \mathrm{C}\right]$ riboflavin fraction.

If ethanol acts by inhibiting the activities of FAD pyrophosphatase and FMN phosphatase, then adding excess FAD or FMN to an ethanol-containing medium would be expected to generate less riboflavin than in a saline-containing medium in which the activities of these enzymes remain intact. The results of this experiment shown in Fig. 3 illustrated significantly less $(P<0.001)$ depression of radioactive riboflavin transport in alcohol-containing medium than in saline-containing medium. Furthermore, in the absence of added FAD or FMN, transport of radioactive riboflavin across the mucosal membrane was similar in the saline-containing medium and the ethanol-containing medium, which indicated that the riboflavin transport process through the mucosal membrane was not appreciably damaged by ethanol.

Since small amounts of acetaldehyde are generated in the gastrointestinal tract after consumption of ethanol, we examined the effects of acetaldehyde on the mucosal transport of riboflavin and dephosphorylation of FAD and FMN. In an experimental design similar to that of the ethanol-containing and saline-containing media, intestinal segments were incubated with $0.2 \%$ acetaldehyde in the presence of FAD or FMN, which resulted in less depression of intracellular $\left[{ }^{14} \mathrm{C}\right]$ riboflavin than with saline. The effect of acetaldehyde at this concentration was not as pronounced as that observed in the presence of ethanol, and riboflavin transport was in fact intermediate between that observed in saline-containing and ethanol-containing media. It is important to note that in the absence of added FAD or FMN, intracellular $\left[{ }^{14} \mathrm{C}\right]$ riboflavin accumulated in $0.2 \%$ acetaldehydecontaining medium alone at a level comparable to that in the saline-containing medium, which indicated that the mucosal membrane transport of riboflavin was not altered significantly by acetaldehyde.

Effects of ethanol and acetaldehyde on the activities of FMN phosphosphatase and FAD pyrophosphatase. To investigate further the direct effects of both ethanol and acetaldehyde on flavin nucleotide absorption, we measured the activities of the two FAD hydrolytic enzymes, FAD pyrophosphatase (FAD $\rightarrow$ FMN) and FMN phosphatase (FMN $\rightarrow$ riboflavin), in extracts of intestinal mucosal cells. Studies were performed with increasing concentrations of ethanol incubated in vitro in the enzyme reaction, and were compared with findings with sucrose as a control.

The data from these studies are in Table II. Both enzymes were inhibited by ethanol in vitro, beginning at a $5 \%$ concentration. At each concentration of ethanol, FMN phosphatase was inhibited to a greater extent than FAD pyrophosphatase.

Since a number of the metabolic effects of ethanol are believed due not to ethanol itself, but to its metabolite, acetaldehyde, activities of these hydrolytic enzymes were assayed after intubation with this agent in vitro. As shown in Table II, acetaldehyde at 10-fold lower concentrations than ethanol also markedly inhibited FAD pyrophosphatase activity in extracts from intestinal mucosal cells. An unexpected and repeatedly 


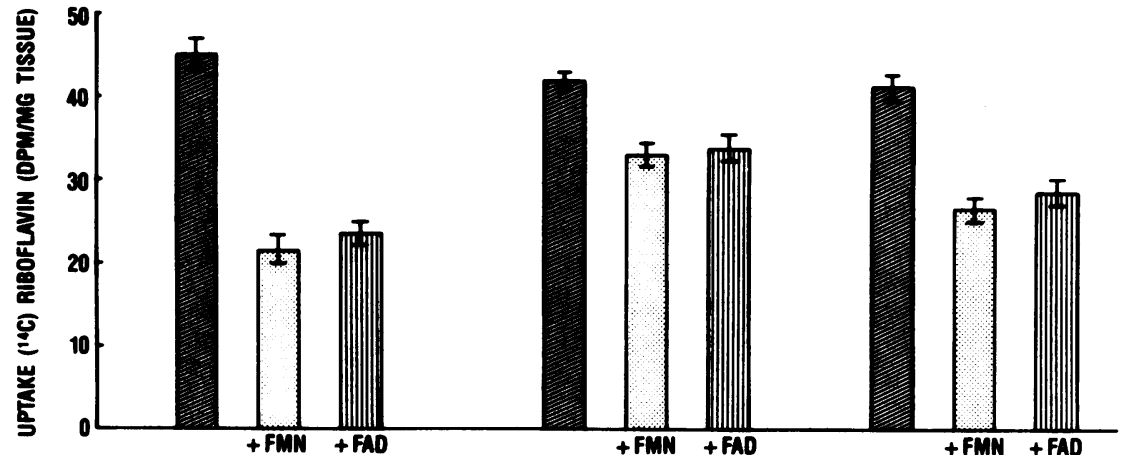

Figure 3. Effects of nonradiolabeled FMN and FAD upon transport of $\left[{ }^{14} \mathrm{C}\right]$ riboflavin across jejunal segments both in the presence and absence of $10 \%$ ethanol and $0.2 \%$ acetaldehyde. confirmed finding is that FMN phosphatase activity was actually increased markedly by acetaldehyde. However, the net effect of acetaldehyde was to diminish the overall hydrolysis of FAD to riboflavin.

\section{Discussion}

The results of the present study suggest that riboflavin deficiency in alcoholism likely arises not only from inadequate intake of this vitamin, but also from specific actions of ethanol, and possibly its major metabolite, acetaldehyde, on several aspects of riboflavin metabolism. Alcohol diminishes the bioavailability of both riboflavin and FAD, which suggests a probable effect on intestinal absorption. However, these findings do not exclude the possibility. that alcohol may interfere additionally with egress of riboflavin from the intestinal mucosa, transport in serum, hepatic uptake, metabolic transformations in tissue, urinary excretion, or other processes.

The fact that the bioavailability of FAD is inhibited by alcohol to an even greater degree than that of riboflavin under these conditions suggests that alcohol has an important action on inhibiting the hydrolysis of FAD to riboflavin, which is required before its absorption. Evidence in support of this hypothesis is provided by the observation that both FAD degradative enzymes, FAD pyrophosphatase and FMN phosphatase, from intestinal mucosa are inhibited in vitro by alcohol. Acetaldehyde also inhibits FAD pyrophosphatase activity, but, curiously, enhances FMN phosphatase activity. Nevertheless, the net effect of these divergent actions of acetaldehyde and the combined effects of ethanol and acetaldehyde are to restrict sharply the amount of riboflavin derived from the hydrolysis of FAD subsequently available for absorption.

The differential effects of alcohol on FAD and riboflavin bioavailability may possibly have clinical implications for nutritional rehabilitation of alcoholic patients. Most food sources of riboflavin are in the form of FAD (17); it would be expected

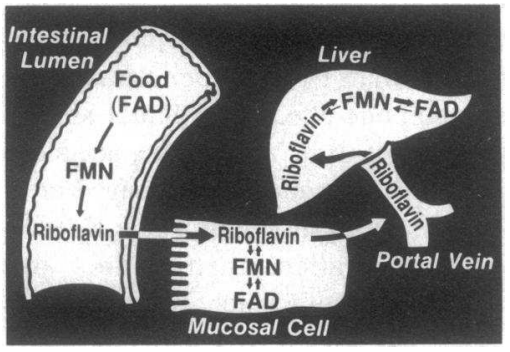

Figure 4. Diagrammatic representation of the hydrolysis of dietary FAD to riboflavin, its intestinal transport, and reconversion to $\mathrm{FAD}$ in liver. that food sources would be less efficiently utilized by the alcoholic patient than vitamin supplements, which are in the form of riboflavin itself. Since the bioavailability of food sources of vitamin $B_{2}$ appears to be affected more than vitamin preparations are by the deleterious effects of ethanol, the initial rehabilitation of riboflavin-deficient alcoholic patients theoretically might be accomplished more quickly and efficiently by vitamin therapy than with food sources. A similar conclusion has been reached with respect to folate, thiamine, and vitamin $B_{6}(37)$. It will be important to determine the duration of the inhibitory effects of alcohol and the effects of chronic intake of alcohol since, in the present study, food sources and alcohol were administered simultaneously. The sequence of events in the conversion of food FAD to hepatic FAD is shown in Fig. 4.

Little attention has been given to the possible role of riboflavin nutriture in determining any of the physiological or clinical disorders associated with alcoholism. Riboflavin deficiency results in a decrease in the removal rate of ethanol (13) and therefore may be one of the factors governing the duration of alcohol action. Although metabolism of acutely administered alcohol is believed to be mediated by the inducible enzyme, alcohol dehydrogenase, chronically administered alcohol is also catabolized

Table II. Activities of FAD Pyrophosphatase and FMN Phosphatase in Extracts from Rat Mucosal Cells after Incubation with Either Ethanol or Acetaldehyde In Vitro

\begin{tabular}{ll}
\hline $\begin{array}{l}\text { FAD pyrophosphatase } \\
\text { activity }\end{array}$ & $\begin{array}{l}\text { FMN phosphatase } \\
\text { activity }\end{array}$ \\
\hline$\%$ control & $\%$ control
\end{tabular}

Ethanol (\%)

$\begin{array}{lll}1 & 97 \pm 1 & 95 \pm 5 \\ 5 & 88 \pm 2 & 66 \pm 6 \\ 10 & 76 \pm 2 & 43 \pm 3 \\ 20 & 35 \pm 4 & 27 \pm 3 \\ \text { cetaldehyde (\%) } & & \\ 0.1 & 85 \pm 5 & 115 \pm 4 \\ 0.5 & 45 \pm 4 & 222 \pm 9 \\ 1.0 & 32 \pm 2 & 255 \pm 7 \\ 2.0 & 11 \pm 3 & 355 \pm 33\end{array}$

All data are shown as percentage of control from three to seven experiments and are expressed as mean \pm SE. FAD pyrophosphatase and FMN phosphatase activities in control samples were $360 \mathrm{dpm}$ FAD lost $/ 20 \mathrm{~min} / \mathrm{mg}$ protein and $740 \mathrm{dpm}$ riboflavin formed $/ 20 \mathrm{~min} / \mathrm{mg}$ protein, respectively. Total protein per assay ranged from 5 to $7 \mathrm{mg}$. 
by a microsomal enzyme system that requires flavin coenzymes $(38-40)$. It has been observed that riboflavin administration normalizes elevated alcohol dehydrogenase activity with ethanol as a substrate (41), and when combined with pyruvate and dihydroxyacetone, prevents fatty liver caused by alcohol (42). Psychotropic drugs, such as chlorpromazine, imipramine, and amitriptyline, which may be administered to or utilized by alcoholic patients, interfere sensitively with riboflavin utilization and may strain further the already depleted riboflavin reserves (43-45). Flavin metabolism in cardiac tissue is particularly sensitive to the action of these agents; thus, riboflavin-deficient alcoholic patients may be at increased risk for developing cardiac arrhythmias with chronic usage of psychotropic drugs $(46,47)$.

While the Wernicke-Korsakoff syndrome in alcoholism is widely attributed to alterations associated with a deficiency of thiamine, it is not generally appreciated that even minor degrees of riboflavin deficiency may have important effects on personality $(22,23,48,49)$. In addition, riboflavin deficiency leads to a depression of antibody-forming cells in the spleen, which results in decreased immune responsiveness in experimental animals and increased susceptibility to infection (50). Riboflavin deficiency alters the tissue and plasma concentrations of phospholipids (20) and increases the rate of biosynthesis of renal prostaglandins (51). In view of the known role of riboflavin in lipid and amino acid metabolism, energy generation and utilization, and vitamin metabolism, riboflavin deficiency caused by alcoholism may have far-reaching implications for health in alcoholic patients.

Further research is needed to determine the precise sites of action of ethanol on intracellular riboflavin metabolism, to clarify food-alcohol-drug interrelations, and to design more sensitive methods for biochemical evaluation of riboflavin status than are currently available.

\section{Acknowledgments}

This investigation was supported by research grants IP30 CA 29502 and CA 08748 from the National Institutes of Health, and by grants from the American Cancer Society, the Distilled Spirits Council of the United States, the Alcoholic Beverage Medical Research Foundation, the Stella and Charles Guttman Foundation, the American Federation for Aging Research Inc., the Loet A. Velmans Fund, the Parenteral Drug Association Foundation for Pharmaceutical Sciences, and the Edward F. Lukoski-Post No. 7096, Veterans of Foreign Wars of the United States.

\section{References}

1. Bonjour, J. P. 1980. Vitamins and alcoholism. V. Riboflavin, VI. Niacin, VII. Pantothenic acid, and VIII. Biotin. Int. J. Vitam. Nutr. Res. 50:425-440.

2. Fennelly, J., O. Frank, H. Baker, and C. M. Leevy. 1964. Peripheral neuropathy of the alcoholic. I. Aetiological role of aneurin and other Bcomplex vitamins. Br. Med. J. 2:1290-1292.

3. Leevy, C. M., H. Baker, W. ten Hove, O. Frank, and G. R. Cherrick. 1965. B-complex vitamins in liver disease of the alcoholic. Am. J. Clin. Nutr. 16:339-346.

4. Rosenthal, W. S., N. F. Adham, R. Lopez, and J. M. Cooperman. 1973. Riboflavin deficiency in complicated chronic alcoholism. Am. J. Clin. Nutr. 26:858-860.

5. Hell, D., and P. Six. 1977. Thiamin-, Riboflavin- und Pyridoxinversorgung bie chronischem Alkoholismus. Dtsch. Med. Wochenschr. 102:962-966.

6. Pitchumoni, C. S., M. Sonnenshein, F. M. Candido, P. Panchach- aram, and J. M. Cooperman. 1980. Nutrition in the pathogenesis of alcoholic pancreatitis. Am. J. Clin. Nutr. 33:631-636.

7. Neville, J. N., J. A. Eagles, G. Samson, and R. E. Olson. 1968. Nutritional status of alcoholics. Am. J. Clin. Nutr. 21:1329-1340.

8. Majumdar, S. K., G. K. Shaw, and A. D. Thomson. 1981. Vitamin utilization status in chronic alcoholics. Int. J. Vitam. Nutr. Res. 51:5458.

9. Beutler, E. 1969. Glutathione reductase: stimulation in normal subjects by riboflavin supplementation. Science (Wash. DC). 165:613615.

10. Tillotson, J. A., and H. E. Sauberlich. 1971. Effects of riboflavin depletion and repletion on the erythrocyte glutathione reductase in the rat. J. Nutr. 101:1459-1466.

11. Bamji, M. S. 1969. Glutathione reductase activity in red blood cells and riboflavin nutritional status in humans. Clin. Chim. Acta. 26: 263-269.

12. Goldsmith, G. A. 1975. Riboflavin deficiency. In Riboflavin. R. S. Rivlin, editor. Plenum Publishing Corp., New York. 221-244.

13. Hietanen, E., U. Koivusaari, M. Laitinen, and A. Norling. 1980. Hepatic drug metabolism during ethanol ingestion in riboflavin-deficient rats. Toxicology. 16:103-111.

14. Hamajima, S., S. Ono, H. Hirano, and K. Obara. 1979. Induction of the FAD synthetase system in rat liver by phenobarbital administration. Int. J. Vitam. Nutr. Res. 49:59-63.

15. Rivlin, R. S., C. E. Menendez, and R. G. Langdon. 1968. Biochemical similarities between hypothyroidism and riboflavin deficiency. Endocrinology. 83:461-469.

16. Fazekas, A. G., and T. Sandor. 1971. Flavin nucleotide coenzyme biosynthesis and its relation to corticosteroidogenesis in the rat adrenal. Endocrinology. 89:397-407.

17. Rivlin, R. S. 1970. Medical progress: riboflavin metabolism. $N$. Engl. J. Med. 283:463-472.

18. Wickramasinghe, R. H. 1974. Adrenodoxin reductase, the flavoprotein component of adrenal mitochondrial steroid hydroxylases. Int. J. Pept. Protein Res. 6:195-201.

19. Taniguchi, M., and M. Nakamura. 1976. Effects of riboflavin deficiency on the lipids of rat liver. J. Nutr. Sci. Vitaminol. 22:135-146.

20. Olpin, S. E., and C. J. Bates. 1982. Lipid metabolism in riboflavindeficient rats. Br. J. Nutr. 47:577-588.

21. Gellene, R., G. R. Cherrick, and C. M. Leevy. 1966. Electron transport in riboflavin deficiency. Fed. Proc. 25:246.

22. Sterner, R. T., and W. R. Price. 1973. Restricted riboflavin: withinsubject behavioral effects in humans. Am. J. Clin. Nutr. 26:150-159.

23. Sturman, J., and R. S. Rivlin. 1975. Pathogenesis of brain dysfunction in deficiencies of thiamine, pantothenic acid, riboflavin and pyridoxine. In Biology of Brain Dysfunction. G. E. Gaull, editor. Plenum Publishing Corp., New York. 425-475.

24. French, S. W. 1965. Effect of chronic ethanol ingestion on liver enzyme changes induced by thiamine, riboflavin, pyridoxine, or choline deficiency. J. Nutr. 88:291-302.

25. Dastur, D. K., N. Santhaderi, E. V. Quadros, F. C. R. Avari, N. H. Wadia, M. M. Desai, and E. P. Bharucha. 1976. The B-vitamins in malnutrition with alcoholism. A model of intervitamin relationships. Br. J. Nutr. 36:143-159.

26. Baines, M. 1978. Detection and incidence of $B$ and $C$ vitamin deficiency in alcohol-related illness. Ann. Clin. Biochem. 15:307-312.

27. Pearson, A. G. M., and A. J. Turner. 1975. Folate-dependent Icarbon transfer to biogenic amines mediated methylenetetrahydrofolate reductase. Nature (Lond.). 258:173-174.

28. Cheng, F. W., B. Shane, and E. L. R. Stokstad. 1975. Pentaglutamate derivatives of folate as substrates for rat liver tetrahydropteroylglutamate methyl transferase and 5,10-methylenetetrahydrofolate reductase. Can. J. Biochem. 53:1020-1027.

29. Anderson, B. B., M. Saary, A. D. Stephens, G. M. Perry, I. C. Lersundi, and J. E. Horn. 1976. Effect of riboflavin on red-cell metabolism of vitamin $\mathrm{B}_{6}$. Nature (Lond.). 264:574-575.

30. Rasmussen, K. M., P. M. Barsa, D. B. McCormick, and D. A. Roe. 1980. Effect of strain, sex, and dietary riboflavin on pyridoxamine 
(pyridoxine) 5 -phosphate oxidase activity in rat tissues. J. Nutr. 110: 1940-2948.

31. Preusch, P. C., and J. W. Suttie. 1981. Vitamin K-dependent reactions in rat liver: role of flavoproteins. J. Nutr. 111:2087-2097.

32. Pekkanen, L., and M. Rusi. 1979. The effects of dietary niacin and riboflavin on voluntary intake and metabolism of ethanol in rats. Pharmacol. Biochem. Behav. 11:575-579.

33. Mezey, E. 1985. Metabolic effects of alcohol. Fed. Proc. 44:134138.

34. Fazekas, A. G., J. Pinto, Y. P. Huang, and R. S. Rivlin. 1978. Age-dependence of thyroxine stimulation of riboflavin incorporation into flavin coenzymes in liver and brain. Endocrinology. 102:641-648.

35. Karasov, W. H., and J. M. Diamond. 1983. A simple method for measuring intestinal solute uptake in vitro. J. Comp. Physiol. 152: 105-116.

36. Akiyama, T., J. Selhub, and I. H. Rosenberg. 1982. FMN phosphatase and FAD pyrophosphatase in rat intestinal brush borders: role in intestinal absorption of dietary riboflavin. J. Nutr. 112:263-268.

37. Baker, H., O. Frank, R. E. Zetterman, K. S. Rajan, W. ten Hove, and G. M. Leevy. 1975. Inability of chronic alcoholics with liver disease to use food as a source of folate, thiamin, and vitamin $\mathrm{B}_{6}$. Am. J. Clin. Nutr. 28:1377-1380.

38. Brodie, B. B., J. R. Gillette, and B. N. LaDu. 1958. Enzymatic metabolism of drugs and other foreign compounds. Annu. Rev. Biochem. 27:427-454.

39. Conney, A. H. 1967. Pharmacological implications of microsomal enzyme induction. Pharmacol. Rev. 19:317-366.

40. Patel, J. M., and S. S. Pawar. 1974. Riboflavin and drug metabolism in adult rats and female rats. Biochem. Pharmacol. 23:1467-1477.

41. Satanovskaya, V. I., Y. M. Ostrovsky, and M. N. Sadovnik. 1981. The liver alcohol and aldehyde dehydrogenases of rats with chronic alcohol intoxication after riboflavin administration. Subst. Alcohol ActionsMisuse. 2:149-152.
42. Stanko, R. T., H. Mendelow, H. Shinozuka, and S. A. Adibi. 1978. Prevention of alcohol-induced fatty liver by natural metabolites and riboflavin. J. Lab. Clin. Med. 91:228-235.

43. Pinto, J., Y. P. Huang, and R. S. Rivlin. 1981. Inhibition of riboflavin metabolism in rat tissues by chlorpromazine, imipramine and amitriptyline. J. Clin. Invest. 67:1500-1506.

44. Pinto, J., M. Wolinsky, and R. S. Rivlin. 1979. Chlorpromazine antagonism of thyroxine-induced flavin formation. Biochem. Pharmacol. 28:597-600.

45. Pelliccione, N., J. Pinto, Y. P. Huang, and R. S. Rivlin. 1983. Accelerated development of riboflavin deficiency by treatment with chlorpromazine. Biochem. Pharmacol. 32:2949-2953.

46. Pinto, J., Y. P. Huang, N. Pelliccione, and R. S. Rivlin. 1982. Cardiac sensitivity to the inhibitory effects of chlorpromazine, imipramine and amitriptyline upon formation of flavins. Biochem. Pharmacol. 31: 3495-3499.

47. Fowler, N. O., O. McCall, T. Chou, J. C. Holmes, and R. B. Hanenson. 1976. Electrocardiographic changes and cardiac arrhythmias in patients receiving psychotropic drugs. Am. J.'Cardiol. 37:223-230.

48. Brin, M., and J. C. Bauernfeind. 1978. Vitamin needs of the elderly. Postgrad. Med. 62:155-163.

49. Rivlin, R. S. 1978. Effects of marginal riboflavin deficiency. In Proceedings of the Western Hemisphere Nutrition Congress. V. P. L. White, editor. Chicago American Medical Association, Chicago. 289294.

50. Kumar, M., and A. E. Axelrod. 1978. Cellular antibody synthesis in thiamin, riboflavin, biotin, and folic acid-deficient rats. Proc. Soc. Exp. Biol. Med. 157:421-423.

51. Pelliccione, N. J., R. Karmali, R. S. Rivlin, and J. Pinto. 1985. Effects of riboflavin deficiency upon prostaglandin biosynthesis in rat kidney. Prostaglandins Leukotrienes Med. 17:349-358. 